\title{
As AgênCIas Reguladoras IndePENDENTES BrasileIRAS: o Caso da Agência Nacional de Vigilância Sanitária
}

\author{
THE BRAZILIAN INDEPENDENT REGULATORY AGENCIES:
} THE CASE OF BRAZILIAN NATIONAL HEALTH SURVEILLANCE AGENCY

Alexandre Santos de Aragão ${ }^{(*)}$

\section{RESUMO}

Na década de 90, surgiram inúmeros órgãos e entidades dotadas de independência frente ao aparelho central do Estado, com especialização técnica e autonomia, inclusive normativa, capazes de direcionar as novas atividades sociais na senda dos interesses públicos juridicamente definidos. Nesse contexto, analisar-se-á de forma mais detida a Agência Nacional de Vigilância Sanitária - ANVISA, criada pela Lei n. 9.782, de 26 de janeiro de 1999, com o propósito de executar as políticas públicas para a área de saúde e vigilância sanitária, delineadas pelo Ministério da Saúde. Assim, constitui objetivo deste trabalho ponderar acerca dos aspectos de independência e autonomia da agência frente ao ambiente regulatório brasileiro, tomando por base as competências a ela atribuídas por sua lei instituidora.

\section{Palavras-chave}

Agências Reguladoras; ANVISA; Regulação.

\section{Abstract}

In the 90's, came into place several organs and entities provided with independence towards the state's central structure, with technical speciality and autonomy, including normative, able to direct the new social activities in

(*) Doutor em Direito do Estado pela Universidade de São Paulo (USP); mestre em Direito Público pela Universidade do Estado do Rio de Janeiro (UERJ); professor de Direito Administrativo da UERJ; Procurador do Estado e advogado. E-mail: — <aragao@rennoadv.com.br>. Recebido em 28.8.09. 
the trail of public interests juridically defined. In this context, the main objective of this paper is to analyze more carefully the Brazilian Health Surveillance Agency - ANVISA, created by federal law 9.782, of January 26 th. 1999, with the purpose of putting into action public policies of health and sanitary vigilance drawn by the Ministry of Health. Thus, it is also aim of this work to examine the aspects of independence and autonomy of this agency, based on its attributions designed by the law 9.782 and taking into account the brazilian regulatory environment.

\section{Keywords}

ANVISA; Regulation; Regulatory Agencies.

\section{AS AGÊNCIAS REGULADORAS INDEPENDENTES BRASILEIRAS}

As agências reguladoras independentes constituem um modelo institucional de Administração Pública, influenciado pelo arquétipo originário dos Estados Unidos da América, que vem sendo adotado na América Latina e na Europa com especial intensidade a partir da década de 80.

O que constitui o núcleo essencial do conceito das agências reguladoras independentes em relação ao modelo tradicional de Administração Pública, dita piramidal, napoleônica ou hierarquizada, é a independência em relação ao Poder Executivo central, independência esta que, tecnicamente, é melhor caracterizada como uma "autonomia reforçada" em relação à que possuem os demais aparatos da Administração Indireta, havendo a insurgência de uma Administração Pública Pluricêntrica(1) ou Multiorganizativa. ${ }^{(2)}$

(1) Vital Moreira, citando Breuer, considera o surgimento de órgãos e entidades públicas autônomas em relação ao Poder estatal central como a "resposta necessária do moderno Estado social ao alargamento das suas tarefas. A autonomização de organismos administrativos é, portanto uma consequência, em termos de diferenciação e especialização, da ampliação e diversificação das tarefas administrativas." Caracterizando a administração pública do Estado pluriclasse como "policêntrica", afirma, desta vez valendo-se de Brohm, que "quanto mais a colectividade se especializa e diferencia técnico-profissionalmente e se pluraliza ético-culturalmente, tanto menor se torna aquilo que é comum a todos e tanto maior necessidade existe de diferenciação político-administrativa para corresponder à diversidade dos apelos feitos aos poderes públicos" (MOREIRA, Vital. Administração autônoma e associações públicas. Coimbra: Coimbra Ed., 1997. p. 30-31 e 35).

(2) "A Administração italiana é - como, aliás, todas as Administrações dos países desenvolvidos - multiorganizativa, no sentido de que a amplitude e a variedade das funções públicas não apenas levaram à perda da unidade da organização do Estado, mas levaram-no também a adotar diversos modelos organizativos. As administrações públicas são, portanto, fragmentadas e diferenciadas. Por este motivo, é preferível dizer que a administração é multiorganizativa, antes que pluralística ou policêntrica. Estes termos muitas vezes não se referem a sujeitos, mas individuam apenas o primeiro (fragmentação), e não o segundo (diferenciação), dos dois caracteres acima indicados" (CASSESE, Sabino. Le basi del diritto amministrativo. 6. ed. Milano: Ed. Garzanti, 2000. p. 189-190). 
Nunca é demais lembrar: toda autonomia é, por definição, limitada; autonomia é a liberdade de agir dentro de limites fixados por uma instância normativa superior. ${ }^{(3)}$

Não há um conceito unívoco de autonomia, conceito que só pode ser formulado em relação a cada autonomia concretamente considerada, uma vez que os mencionados limites podem variar imensamente. ${ }^{(4)}$

Podemos afirmar, dessa maneira, que todas as entidades da Administração Indireta possuem alguma autonomia, mas temos uma espécie de entidade da Administração Indireta - as agências reguladoras independentes - cuja autonomia, se comparada com a maioria das demais, é bem mais intensa, já que as suas leis instituidoras fixam competências próprias e garantias para o exercício delas de forma bem mais firme da que faz ordinariamente.

As agências reguladoras, apesar das variações que possuem em cada direito positivo e mesmo no interior de cada um deles, podem, no Direito Positivo Brasileiro, ser identificadas pela conjunção de quatro fatores:

(a) competências regulatórias, ou seja, atribuições normativas, administrativas stricto sensu e contratuais, pelas quais o Estado, de maneira restritiva da liberdade privada ou meramente indutiva, determina, controla, ou influencia o comportamento dos particulares, evitando que lesem os interesses sociais definidos no marco da Constituição e orientando-os em direções socialmente desejáveis;

(b) procedimento especial de nomeação dos membros do seu colegiado diretor, com a prévia aprovação pelo Poder Legislativo (no caso da União, pelo Senado Federal) dos nomes indicados pelo Chefe do Poder Executivo;

(c) autonomia orgânica, sendo os seus dirigentes nomeados por prazo determinado, vedada a exoneração ad nutum e sem prévio contraditório; e

(3) "A autonomia de toda instituição não é absoluta, podendo ser apenas relativa, resultando a sua configuração de determinadas variáveis" (ROMANO, Santi. L'ordinamento giuridico. 2. ed. Firenze: Sansoni, 1945. p. 22).

(4) "Autonomia designa genericamente o espaço de liberdade de conduta de um ente face a outro. Concretamente no âmbito das pessoas colectivas públicas ela exprime a liberdade dos entes infraestaduais face ao Estado, ou seja, a "relativa independência em relação ao poder central". Conforme os diversos campos em que essa liberdade de conduta pode manifestar-se, assim se pode falar em autonomia regulamentar, autonomia administrativa (stricto sensu), autonomia patrimonial e financeira etc. Neste sentido, a autonomia é uma questão de grau: pode ir de quase nada até à independência quase total. Nuns casos pode consistir senão na mera autonomia jurídica (existência de personalidade jurídica), sem nenhuma liberdade de acção; noutros casos pode ir até à mais ampla liberdade de decisão dentro da esfera de acção que lhe seja confiada ('administração independente')" (MOREIRA, Vital. op. cit., p. 69-70). 
(d) autonomia funcional, pela qual constituem a última instância administrativa - vedação de anulação ou revogação dos seus atos pelo Poder Executivo central (vedação do recurso hierárquico impróprio ou de revisão ex officio), que apenas pode fixar as diretrizes gerais de políticas públicas a serem seguidas, observadas, naturalmente, as políticas já previamente estabelecidas pelo Poder Legislativo.

As agências reguladoras possuem, portanto, do ponto de vista da autonomia frente ao Executivo central, dois pontos básicos da sua própria existência conceitual: vedação de exoneração ad nutum e ser a última instância no âmbito da Administração Pública. Sem um deles, a entidade poderá até continuar existindo, mas seguramente não será mais uma agência reguladora.

No Brasil, as agências reguladoras são consideradas um instituto novo no Direito Público, surgido apenas a partir da década de noventa. A afirmação, contudo, se não é falsa, não é inteiramente verdadeira. Se, por um lado, a divisão da Administração Pública em mais de um único centro de poder é um fenômeno muito mais amplo do que o surgimento das recentes agências reguladoras, não há de se menosprezar a importância destas, principalmente diante do contexto de desestatização e desregulamentação em que surgiram.

Este novo contexto fez com que uma série de institutos e competências administrativas sempre presentes em nosso Direito fossem submetidos a uma releitura, atualizando-os às mais modernas leis de regulação da economia, cuja implementação, em sua maior parte, incumbe às agências reguladoras independentes criadas em seu bojo.

Admitimos que as agências reguladoras foram, em um primeiro momento, adotadas no Brasil em decorrência da desestatização de serviços públicos, o que está muito longe de significar que sejam por essência um instrumento de desregulação ou da desestatização, ${ }^{(5)}$ até mesmo porque logo começaram a ser criadas agências reguladoras, não mais de serviços públicos, mas de atividades econômicas stricto sensu, que propiciaram um aumento da intervenção estatal sem precedentes nestes setores, como foi o caso da Agência Nacional de Vigilância Sanitária - ANVISA, objeto desse trabalho. ${ }^{(6)}$

(5) De forma alguma desestatização pode ser equiparada a desregulação. Trata-se de dois fenômenos distintos, que podem coincidir ou não.

(6) Se a participação do Estado enquanto agente normativo, intervindo no domínio econômico, através de empresas estatais, arrefeceu, a intervenção sobre o domínio econômico, enquanto agente regulador foi bastante intensificada, principalmente em razão do modelo de agências reguladoras que passou a ser adotado no Brasil" (SCAFF, Fernando Facury. Responsabilidade civil do Estado intervencionista. 2. ed. Rio de Janeiro: Renovar, 2001. p. 12). Devemos também nunca perder de vista que as "reformas regulatórias em países subdesenvolvidos devem ser pensadas no âmbito das características e interesses próprios desses países - e não em função dos interesses das potências que as incentivam e cobram" (MATTOS, Paulo Todescan Lessa; COUTINHO, Diogo Rosenthal. Os desafios da reforma regulatória brasileira. Revista da Pós-Graduação da Faculdade de Direito da Universidade de São Paulo, São Paulo, v. 1, p. 84-85, 1999). 
Sendo assim, podemos constatar que, passados alguns anos da criação das primeiras agências reguladoras, revela-se que a busca deste modelo organizativo destina-se a regular, antes do que especificamente serviços públicos desestatizados, as atividades que em geral possuem uma especial sensibilidade para a coletividade, a respeito das quais os interesses são fortes, múltiplos e conflitantes, notadamente atividades que possuem elevado potencial de comoção da opinião pública, ${ }^{(7)}$ entre as quais se incluem, obviamente, os serviços públicos e as atividades de interesse sanitário.

O surgimento das agências reguladoras no Brasil constitui, portanto, fenômeno muito mais profundo do que o de sua utilização episódica para o aumento ou para a retração da intervenção do Estado na economia. No dizer de Luciano Parejo Alfonso, em lição perfeitamente aplicável à nossa realidade, estas entidades dotadas de autêntica autonomia não são

um substitutivo da supostamente degradada objetividade da Administração Pública clássica. Muito pelo contrário, são uma continuação, por outros meios, da mesma e única objetividade administrativa, ali, e apenas ali, onde a progressiva complexidade da sociedade atual — de cujo 'arranjo' o 'Estado é hoje o responsável universal', qualificado em nosso caso de Estado social - conduziu o sistema ordinário de poderes-fontes a um ponto limite a partir do qual se torna incapaz de satisfatoriamente gerar a racionalidade jurídica necessária para sustentar o processo de realização, com objetividade, do interesse geral próprio da Administração tradicional ou clássica. Está-se, assim, diante de uma manifestação específica do ponto de ruptura de um sistema geral ante a emergência e desenvolvimento, em seu seio, de um subsistema diferenciado, cuja absorção - nas palavras de Garcia Pelayo - seria impossível a partir da racionalidade global própria daquele, sendo imperativa a atenção e a incorporação de dito subsistema para a recuperação da coesão do sistema em um novo equilíbrio. ${ }^{(8)}$

Quanto à estrutura administrativa em si, agências reguladoras independentes constituem uma novidade no Brasil mais pelo óbice jurisprudencial aposto pelo Supremo Tribunal Federal no passado, do que por uma suposta desacolhida do modelo pelo legislador.

Com efeito, há algumas décadas começou a ser instituída, via Legislativo, uma série de autarquias de regime especial a cujos dirigentes a lei restringia o poder de exoneração do Chefe do Poder Executivo ao estabelecer a sua nomeação por mandato determinado. ${ }^{(9)}$ O STF, contudo, à época,

(7) É o caso justamente da Agência Nacional de Vigilância Sanitária - ANVISA, criada, não nos esqueçamos, após o escândalo da venda de medicamentos falsos e adulterados. O mesmo se pode dizer da Agência Nacional de Saúde Suplementar - ANS, instituída após os protestos da imprensa e a insatisfação da opinião pública com uma série de atitudes das empresas de planos de saúde. (8) ALFONSO, Luciano Parejo. Prefácio. In: RODRÍGUEZ, Andrés Betancor. Las administraciones independientes. Madrid: Tecnos, 1994. p. 17.

(9) Por exemplo, o Instituto de Aposentadoria e Pensões dos Industriários, criado pela Lei n. 3.807/60. 
considerou inconstitucional este reforço de autonomia por violar o poder de direção do Presidente da República sobre toda a Administração pública. Esta posição jurisprudencial foi consolidada pela Súmula n. 25, que dispõe: "A nomeação a termo não impede a livre demissão, pelo Presidente da República, de ocupante de cargo dirigente de autarquia". Apenas recentemente, no julgamento da liminar requerida na ADIN n. 1949-0, este entendimento foi revertido.

Afirmando a inconstitucionalidade da restrição à livre exoneração pelo Presidente da República, o Ministro Relator Ribeiro da Costa a fundamentou, entre os que ainda poderiam em tese ser invocados, nos seguintes argumentos: (a) necessidade de ajudar o novo presidente a executar o seu programa de governo; (b) evitar que um governante vinculasse o sucessor às suas políticas; (c) a inexistência em nosso direito da figura da estabilidade temporária; (d) só existem cargos vitalícios, efetivos e em comissão, não contemplando a Constituição qualquer outra espécie; e (e) uma visão centralizadora napoleônica da Administração Pública ("Seria então um administrador. Eu quero e mando! Só assim o entendo, e admito."(10) - sic)

O Ministro Victor Nunes Leal, com o espírito democrático e progressista que sempre caracterizou o seu pensamento, emitiu erudito e profundo voto, ${ }^{(11)}$ do qual constam os seguintes principais fundamentos da constitucionalidade da vedação de exoneração ad nutum: (a) a Constituição dispunha (e dispõe - art. 84, XXV) que incumbe ao Presidente prover os cargos públicos na forma da lei, o que deve ser entendido não como alusivo a meras formalidades, mas como "na conformidade com a lei, consoante a lei, segundo a lei, segundo o que dispuser a lei...";(12) (b) o exemplo dos E.U.A., de grande relevância tendo em vista a "identidade dos regimes políticos em seus traços essenciais, como também pela circunstância de que os americanos têm praticado o presidencialismo, que inventaram, desde mais de cem anos antes de nós";(13) (c) a figura da Presidência da República deve ser considerada impessoalmente, independentemente da pessoa que a estiver exercendo, e, colocada desta forma, o Chefe do Poder Executivo sempre terá participado da nomeação; (d) o respeito à discricionariedade do Poder Legislativo acerca da melhor estrutura organizacional para implementar as suas políticas; (e) citando o caso Humphrey, afirma que "quem exerce o cargo só enquanto agrada a outro, não pode, por isso mesmo, manter uma atitude de independência ante a vontade desse outro";(14) (f) "a Constituição não ampara a interpretação napoleônica do Executivo";(15) (g) não se trata

(10) Revista Trimestral de Jurisprudência, 25/60.

(11) A decisão foi por cinco votos a quatro.

(12) Revista Trimestral de Jurisprudência, 25/62.

(13) Revista Trimestral de Jurisprudência, 25/64.

(14) Revista Trimestral de Jurisprudência, 25/66.

(15) Revista Trimestral de Jurisprudência, 25/67, grifamos. 
de "estabilidade temporária", mas sim de uma restrição legal à exoneração arbitrária, semelhante à que protege os funcionários públicos antes da aquisição da estabilidade (cf. Súmula 21(16)); (h) estes dirigentes, nomeados a termo determinado, não exercem propriamente "mandato", sendo inadequada a aproximação com o mandato civil ou com o mandato político; (i) o risco do Presidente impor ao seu sucessor o prolongamento da sua política se dá apenas na instalação da entidade, já que, decorridos alguns anos, a agência contará com dirigentes nomeados por diversos Presidentes da República; (j) "a cautela tomada pelo Legislador, ao instituir a investidura por prazo certo, não se dirige, especificamente, contra este ou aquele governante, particularmente considerado. É uma garantia de independência do exercício das funções dos dirigentes contra qualquer ocupante da Chefia do Poder Executivo, mesmo contra o Presidente que tiver feito as nomeações"; (17) (I) é ao Legislador que compete definir se as suas políticas serão melhor alcançadas por dirigentes subordinados ao Chefe do Executivo ou dele independentes.

Em passagem lapidar o pensamento do MINISTRO VICTOR NUNES LEAL, que encampamos, pode ser sintetizado: "A investidura de servidor público por prazo certo, eis uma providência que se integra, com toda a naturalidade, no regime de autonomia administrativa atribuído, por lei, a certos órgãos. Visa a investidura de prazo certo a garantir a continuidade de orientação e a independência de ação de tais entidades autônomas, de modo que os titulares, assim protegidos contra as injunções do momento, possam dar plena execução à política adotada pelo Poder Legislativo, ao instituir o órgão autônomo, e ao definir-Ihe as atribuições".(18)

O relevante desta posição do STF é a afirmação de que um Poder Executivo presidencialista, mais especificamente o nosso presidencialismo, tal como configurado na CF/88, não implica necessariamente em um Executivo centralizador e napoleônico, que possa determinar o comportamento de todas as entidades da Administração. Foi expressamente refutada a posição do Min. Ribeiro da Costa, para quem, vale apenas repisar, "Seria então um administrador. Eu quero e mando! Só assim o entendo, e admito" - sic. Parece, data venia, que o parecer-normativo ressuscitou essa outra visão do Poder Executivo.

Quanto à autonomia funcional (última instância administrativa), a polêmica existiu, mas, pelo menos até a edição do Parecer-normativo n. 51/2006 da Advocacia Geral da União, ${ }^{(19)}$ não chegou a ser tão intensa, até porque

(16) "Súmula 21: Funcionário em estágio probatório não pode ser exonerado nem demitido sem inquérito ou sem as formalidades legais de apuração de sua capacidade".

(17) Revista Trimestral de Jurisprudência, 25/71.

(18) Revista Trimestral de Jurisprudência, 25/63, os grifos são do próprio Ministro.

(19) A esse respeito, remetemos o leitor ao nosso SUPERVISÃO Ministerial das Agências Reguladoras: limites, possibilidades e o parecer AGU n. AC - 51. Revista de Direito Administrativo, v. 245, p. 237-262, 2007. 
seria ilógico e inútil assegurar todo um arcabouço institucional de proteção da autonomia, inclusive com "mandato" dos seus dirigentes e receitas próprias, se o Executivo central pudesse rever as suas decisões, convolando as agências em apenas uma etapa do processo administrativo a ser percorrido pelos administrados.

Examinando o Direito brasileiro positivo, de pronto podemos afirmar que nenhuma lei prevê a existência de recurso administrativo hierárquico impróprio contra as decisões das agências reguladoras, o que por si só bastaria para eliminar tal possibilidade em razão da vetusta doutrina do pas de tutelle sans texte, pas de tutelle au-delà du texte, ${ }^{(20)}$ decorrente da personificação jurídica das entidades da Administração Indireta, que não são meros órgãos despersonalizados - partes integrantes do corpo do Ente estatal.

Podemos, assim, de acordo com a configuração dada pelas respectivas leis instituidoras, ${ }^{(21)}$ incluir todas as agências reguladoras brasileiras no seguinte conceito juspositivo: autarquias de regime especial, dotadas de considerável autonomia frente à Administração centralizada, incumbidas do exercício de funções regulatórias e dirigidas por colegiado cujos membros são nomeados por prazo determinado pelo Presidente da República, após prévia aprovação pelo Senado Federal, vedada a exoneração ad nutum, ou seja, em razão da pura e simples vontade do Chefe do Poder Executivo.

Vale dizer que não há maior grau de autonomia que advenha pura e simplesmente da mera expressão "autarquia de regime especial", mas sim do regime jurídico objetivamente dado pela lei instituidora da entidade, que delineie o grau de autonomia conferida a cada uma delas.

\section{A AGÊNCIA NACIONAL DE VIGILÂNCIA SANITÁRIA — ANVISA}

A Agência Nacional de Vigilância Sanitária - ANVISA foi criada pela Lei n. 9.782/99, regulamentada pelo Decreto n. 3.029, de 16 de abril de 1999, e pela Portaria ANVISA n. 593, de 24 de agosto de 2000, que aprovou o seu Regimento Interno.

De acordo com referida lei, são atribuídas à Agência amplas competências, inclusive normativas, com relação a vários setores econômicos pri-

(20) "O controle administrativo ou tutela administrativa, segundo generalizada lição doutrinária, exerce-se nos limites da lei. Não se presume. Existirá quando, como e na forma prevista em lei" (MELLO, Celso Antônio Bandeira de. Curso de direito administrativo. 11. ed. São Paulo: Malheiros Ed., 1999. p. 147, grifamos).

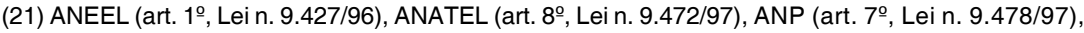

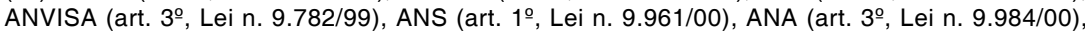
ANTT e ANTAQ (art. 21, Lei n. 10.233/01), ANCINE (art. 5으, MP n. 2.219/01). A mesma denominação foi adotada pelas leis criadoras das agências reguladoras dos demais entes da Federação. 
vados que geram potencial de risco à saúde pública, como os medicamentos, tabaco, alimentos, bebidas, equipamentos de exames médicos etc. (cf. art. 15 c/c Anexo II da Lei n. 9.782/99).

A noção de regulação, com efeito, implica a integração de diversas funções: pressupõe que um quadro seja imposto às atividades econômicas, devendo respeitar um certo equilíbrio dos interesses das diversas forças sociais presentes. Este quadro normativo é estabelecido por decisões gerais e abstratas, constantes geralmente de regulamentos; pela aplicação concreta das suas regras; e pela composição dos conflitos que delas advêm, dando lugar, nestas duas últimas hipóteses, a decisões individuais. ${ }^{(22)}$ Há, portanto, três poderes inerentes à regulação: aquele de editar a regra, o de assegurar a sua aplicação e o de reprimir as infrações. ${ }^{(23)}$

De acordo com o art. $7^{\circ}$ da Lei n. 9.782/99, constituem competência da ANVISA, por exemplo, "I - coordenar o Sistema Nacional de Vigilância Sanitária; II - fomentar e realizar estudos e pesquisas no âmbito de suas atribuições; III - estabelecer normas, propor, acompanhar e executar as políticas, as diretrizes e as ações de vigilância sanitária; IV — estabelecer normas e padrões sobre limites de contaminantes, resíduos tóxicos, desinfetantes, metais pesados e outros que envolvam risco à saúde; (...) VI - administrar e arrecadar a taxa de fiscalização de vigilância sanitária, instituída pelo art. 23 desta Lei; VII - autorizar o funcionamento de empresas de fabricação, distribuição e importação dos produtos mencionados no art. 8 desta Lei e de comercialização de medicamentos; VIII — anuir com a importação e exportação dos produtos mencionados no art. 8을 desta Lei; IX — conceder registros de produtos, segundo as normas de sua área de atuação; $X$ - conceder $\mathrm{e}$ cancelar o certificado de cumprimento de boas práticas de fabricação; (...) XIV - interditar, como medida de vigilância sanitária, os locais de fabricação, controle, importação, armazenamento, distribuição e venda de produtos e de prestação de serviços relativos à saúde, em caso de violação da legislação pertinente ou de risco iminente à saúde; XV — proibir a fabricação, a importação, o armazenamento, a distribuição e a comercialização de produtos e insumos, em caso de violação da legislação pertinente ou de risco iminente à saúde", dentre outras (art. 7ํㅜ).

O art. 3ำ da Lei n. 9.782/99 apresenta os aspectos de independência da ANVISA para o exercício de suas competências, in verbis:

(22) CATTANEO, Salvatore. "Agencies" e "Regulation" nel Regno Unido. In: Le autorità indipendenti: de fattori evolutivi ad elementi della transizione nel diritto pubblico italiano. Milano: Giuffrè, 1999. p. 263. (23) GENTOT, Michel. Les autorités administratives indépendantes. 2. ed. Paris: Ed. Montchrestien, 1994. p. 41. Na doutrina nacional também se observa que aos órgãos e entidades reguladores "cabe não apenas operacionalizar a regulação contida em lei (normativa), através da competência que lhe é outorgada para fiscalizar e aplicar sanções, mas também complementar tal corpo normativo com regulamentos próprios, além de possuir competência para também dirimir conflitos" (cf. MENDES, Conrado Hübner. Reforma do Estado e agências reguladoras. In: SUNDFELD, Carlos Ari. (Coord.). Direito administrativo econômico. São Paulo: Malheiros Ed., 2000. p. 118). 
Art. 3ํ - Fica criada a Agência Nacional de Vigilância Sanitária, autarquia sob regime especial, vinculada ao Ministério da Saúde, com sede e foro no Distrito Federal, prazo de duração indeterminado e atuação em todo território nacional.

Parágrafo único - A natureza de autarquia especial conferida à Agência é caracterizada pela independência administrativa, estabilidade de seus dirigentes e autonomia financeira.

Em sentido semelhante dispõe o art. 4ำ ao afirmar que "a Agência atuará como entidade administrativa independente, sendo-Ihe assegurada, nos termos desta Lei, as prerrogativas necessárias ao exercício adequado de suas atribuições."

Tal independência é reforçada pelo art. 1ํ do Decreto n. 3.029/99, que confirma a natureza de autarquia especial da agência e a sua independência. ${ }^{(24)}$

Ainda como indicativo da sua independência, a ANVISA é expressamente qualificada, pelo art. $15, \S 2^{\circ}$, da Lei n. 9.782/99, como a última instância administrativa de julgamento de recursos administrativos:

$\S 2^{\circ}$ Dos atos praticados pela Agência caberá recurso à Diretoria Colegiada, com efeito suspensivo, como última instância administrativa.

A Lei n. 9.782/99 não prevê o recurso hierárquico impróprio, isto é, o recurso endereçado a autoridade exógena à estrutura hierárquica da autarquia (como, por exemplo, o Ministro da Saúde ou o Presidente da República). A prerrogativa da Diretoria Colegiada para julgar em última instância as matérias de competência da autarquia é confirmada pelo art. 11 do Decreto n. 3.029/99, que determina que "compete à Diretoria Colegiada, a responsabilidade de analisar, discutir e decidir, em última instância administrativa, sobre matérias de competência da autarquia".

Com base no exposto, verifica-se a plena independência administrativa da Diretoria Colegiada da ANVISA, que tomará suas decisões sem que estas possam ser reapreciadas pelo Ministério da Saúde ou por qualquer autoridade da Administração Central. A interferência das autoridades políticas na atuação da Agência deve se dar tão somente por meio da formulação das políticas públicas de vigilância sanitária e saúde, conforme aduz o art. $2^{\circ}$ da Lei n. 9.782/99.

(24) Art. 1ำ A Agência Nacional de Vigilância Sanitária, autarquia sob regime especial, criada pelo art. $3^{\circ}$ da Lei n. 9.782, de 26 de janeiro de 1999, com personalidade jurídica de direito público, vincula-se ao Ministério da Saúde.

§ 1ำ A natureza de autarquia especial, conferida à Agência, é caracterizada pela independência administrativa, estabilidade de seus dirigentes e autonomia financeira.

$\S 2$ ㅇ A Agência atuará como entidade administrativa independente, sendo-lhe assegurado, nos termos da Lei n. 9.782, de 1999, as prerrogativas necessárias ao exercício adequado de suas atribuições. 
Cumpre às agências "interpretar as políticas públicas, por meio de conceitos técnicos, com vistas à sua execução eficiente, devendo resultar, justificadamente, de uma ponderação entre os custos e os benefícios envolvidos (...). A lei, como manifestação do núcleo estratégico do Estado, fixa uma política setorial e precisa seus objetivos, criando barreiras (prevenção), programas e resultados a serem implementados no exercício da função regulatória". ${ }^{(25)}$

Ainda no que toca à independência da ANVISA, dispõe o art. 12 da Lei n. 9.782/99 que a exoneração dos membros da sua Diretoria colegiada (arts. 10 a 14) só poderá ser promovida nos quatro meses iniciais do mandato, findos os quais será assegurado seu pleno e integral exercício, salvo nos casos de prática de ato de improbidade administrativa, de condenação penal transitada em julgado e de descumprimento injustificado do contrato de gestão da autarquia.

A Lei n. 9.782/99 também confere patrimônio próprio à agência, ex vi do art. 21. O dispositivo em apreço determina que "constituem patrimônio da Agência os bens e direitos de sua propriedade, os que lhe forem conferidos ou que venha adquirir ou incorporar." O art. 22 do texto legislativo arrola os valores que integram a receita da autarquia.

Ademais, constata-se que a Lei n. 9.782/99 prevê também a instituição da "Taxa de Fiscalização de Vigilância Sanitária", cujo fato gerador é a prática dos atos de competência da Agência Nacional de Vigilância Sanitária. ${ }^{(26)}$

(25) SOUTO, Marcos Juruena Villela. Direito administrativo regulatório. Rio de Janeiro: Lúmen Júris, 2002. p. 42-43. Não há, contudo, como tecer uma delimitação minimamente precisa do que sejam as políticas públicas e de até que ponto pode atuar o Executivo central sem ingressar no âmbito da sua implementação ou de até onde pode atuar a agência sem que seja acusada de violar políticas públicas. É intuitivo, portanto, que fixar o cabimento de determinado recurso com base na delimitação dessas competências enseja uma válvula de escape para todos os interesses contrariados pela agência, sejam particulares, sejam da Administração pública central, violando todo o arcabouço institucional conferido às agências reguladoras justamente para assegurar que esses interesses fossem regulados de forma técnica, independente e equidistante.

(26) Art. 23 - Fica instituída a Taxa de Fiscalização de Vigilância Sanitária.

$\S 1$ 으 - Constitui fato gerador da Taxa de Fiscalização de Vigilância Sanitária a prática dos atos de competência da Agência Nacional de Vigilância Sanitária constantes do Anexo II.

$\S 2^{\circ}$ - São sujeitos passivos da taxa a que se refere o caput deste artigo as pessoas físicas e jurídicas que exercem atividades de fabricação, distribuição e venda de produtos e a prestação de serviços mencionados no art. 8을 desta Lei.

$\S 3^{\circ}$ - A taxa será devida em conformidade com o respectivo fato gerador, valor e prazo a que refere a tabela que constitui o Anexo II desta Lei.

$\S 4$ ㅇ - A taxa deverá ser recolhida nos prazos dispostos em regulamento próprio da Agência.

$\S 5^{\circ}-\mathrm{A}$ arrecadação e a cobrança da taxa a que se refere este artigo poderá ser delegada aos Estados, ao Distrito Federal e aos Municípios, a critério da Agência, nos casos em que por eles estejam sendo realizadas ações de vigilância, respeitado o disposto no $\S 1^{\circ}$ do art. $7^{\circ}$ desta Lei. 


\section{CONSIDERAÇÕES FINAIS}

Como visto, as agências reguladoras brasileiras são autarquias de regime especial, dotadas de considerável autonomia frente à Administração centralizada, incumbidas do exercício de funções regulatórias.

O grau de autonomia atribuído a cada Agência Reguladora será delineado objetivamente pela lei instituidora da entidade, não decorrendo simplesmente da expressão "autarquia de regime especial".

No caso da Agência Nacional de Vigilância Sanitária - ANVISA, vimos que a Lei instituidora the confere uma série de competências no âmbito do Sistema de Vigilância Sanitária Nacional, garantindo, ainda, a sua independência com relação ao Poder Executivo Central por meio da previsão, por exemplo, de limites à revisão das decisões finais de sua Diretoria Colegiada (vedação ao recurso hierárquico impróprio), bem como o estabelecimento de mandato fixo para seus dirigentes.

Esses mecanismos de garantia de autonomia devem, juntamente com o aumento da sua transparência e atuação equânime (audiências e sessões públicas etc.), ser preservados, implementados e aperfeiçoados, tendo em vista que no substrato da criação dessas entidades está justamente a necessidade de imunização da regulação técnica dos setores da economia contra as variações de curto e médio prazo da arena política, imunidade sem a qual a implementação de políticas públicas teria grandes chances de ficar comprometida por interesses parciais passageiros.

\section{REFERÊNCIAS BIBLIOGRÁFICAS}

ALFONSO, Luciano Parejo. Prefácio. In: RODRíGUEZ, Andrés Betancor. Las administraciones independientes. Madrid: Tecnos, 1994.

CASSESE, Sabino. Le basi del diritto amministrativo. 6. ed. Milano: Ed. Garzanti, 2000.

CATTANEO, Salvatore. "Agencies" e "Regulation" nel Regno Unido. In: Le autorità indipendenti: de fattori evolutivi ad elementi della transizione nel diritto pubblico italiano. Milano: Giuffrè, 1999.

GENTOT, Michel. Les autorités administratives indépendantes. 2. ed. Paris: Ed. Montchrestien, 1994.

MATTOS, Paulo Todescan Lessa; COUTINHO, Diogo Rosenthal. Os desafios da reforma regulatória brasileira. Revista da Pós-Graduação da Faculdade de Direito da Universidade de São Paulo, São Paulo, v. 1, 1999.

MELLO, Celso Antônio Bandeira de. Curso de direito administrativo. 11. ed. São Paulo: Malheiros Ed., 1999. 
MENDES, Conrado Hübner. Reforma do Estado e agências reguladoras. In: SUNDFELD, Carlos Ari. (Coord.). Direito administrativo econômico. São Paulo: Malheiros Ed., 2000.

MOREIRA, Vital. Administração autônoma e associações públicas. Coimbra: Coimbra Ed., 1997.

ROMANO, Santi. L'ordinamento giuridico. 2. ed. Firenze: Sansoni, 1945.

SCAFF, Fernando Facury. Responsabilidade civil do Estado intervencionista. 2. ed. Rio de Janeiro: Renovar, 2001.

SOUTO, Marcos Juruena Villela. Direito administrativo regulatório. Rio de Janeiro: Lúmen Júris, 2002.

SUPERVISÃO Ministerial das Agências Reguladoras: limites, possibilidades e o parecer AGU n. AC - 51. Revista de Direito Administrativo, v. 245, p. 237-262, 2007. 